Gut, 1986, 27, 78-85

\title{
Effect of toxin A and B of Clostridium difficile on rabbit ileum and colon
}

\author{
T J MITCHELL, J M KETLEY, S C HASLAM, J STEPHEN, D W BURDON, \\ D C A CANDY, AND R DANIEL \\ From the Department of Microbiology, University of Birmingham, Birmingham, Department of \\ Microbiology, General Hospital, Birmingham, Institute of Child Health, Birmingham, and Pfizer Central \\ Research, Sandwich, Kent
}

SUMmARY The effect of purified toxin A and partially purified toxin $B$ on rabbit ileum and colon was investigated. Toxin A caused tissue damage which was followed by permeability changes and fluid accumulation in both tissues. Toxin A did not increase the permeability of the colon to the extent observed for ileum; secreted fluid contained less protein of plasma origin. Toxin B had no effect on either tissue. Secretory aid tissue damaging properties of crude $C$ difficile toxins were found to be due to toxin $\mathrm{A}$.

Clostridium difficile is now known to be the primary cause of antibiotic associated pseudomembranous colitis. ${ }^{12}$ The organism produces four toxins of possible relevance in the pathogenesis of the disease: an enterotoxin (toxin A), ${ }^{34}$ a cytotoxin (toxin B),${ }^{34}$ a motility altering factor ${ }^{5}$ and a recently described labile toxin which causes clear fluid accumulation in rabbit ileal loops. ${ }^{6}$ In contrast with cholera and Escherichia coli heat labile toxins which induce fluid accumulation with no tissue damage, ${ }^{78}$ toxin A of $C$ difficile causes fluid accumulation with mucosal damage in several animal models: rabbit ileal loop test ${ }^{9}{ }^{10}$ hamster ileal loop ${ }^{9}$ and hamster caecal loop. ${ }^{10}$ Toxin $\mathrm{A}$ is also lethal to mice and causes increased vascular permeability in guinea pig skin. ${ }^{9}$ Thus toxin $\mathrm{A}$ appears to have a mode of action different to that of cholera or $E$ coli heat labile toxins because it causes tissue damage in combination with fluid secretion. Toxin B does not cause fluid accumulation in rabbit ileal loops ${ }^{11}$ or hamster ileal loops. ${ }^{12}$ There are discrepancies, however, as to its tissue damag' $\cdot \mathrm{g}$ properties: Taylor et al ${ }^{9}$ report that only limited histological damage is caused to mucosal epithelium of hamster caeca whereas Libby et al $^{12}$ showed substantial damage. Toxin $B$ is cytotoxic for a variety of cell lines in vitro but the relevance of this observation to fluid secretion in the intestine is unclear.

Address for correspondence: Dr J Stephen, Department of Microbiology South West Campus, University of Birmingham, PO Box 363, Birmingham B15 2TT

Received for publication 9 April 1985
The aim of the present study was to determine whether mucosal injury is a prerequisite for secretion induced by toxin A and to define for both ileum and colon the nature of the secretory response in terms of protein accumulation and permeability changes.

\section{Methods}

ANIMALS

Male New Zealand white rabbits (2-2.5 kg; Regal Rabbits, Surrey) were used in all studies. Animals were starved overnight but were given water ad libitum.

\section{TOXIN PRODUCTION}

C difficile strain 23289 (isolated from a clinical case of pseudomembranous colitis at the General Hospital, Birmingham and found to be a good toxin producer in vitro; unpublished observations) was grown in medium described by Stephen et al ${ }^{11}$ with two modifications. First, medium was initially passed through an H1P10-8 hollow fibre filter (Amicon) to ensure that the medium contained only low molecular weight materials. Organisms were grown in $500 \mathrm{ml}$ ultrafiltrate for 15 hours; the whole of this starter culture was used to inoculate a $60 \mathrm{l}$ batch of ultrafiltrate. After four hours of incubation, filter sterilised clindamycin (enhances toxin A production; unpublished observations) was added and incubation continued for four days. The second modification involved concentrating the culture 
using an H1X50-8 hollow fibre filter (Amicon) which removed low molecular weight material - and the retentate $(600 \mathrm{ml})$ clarified by centrifugation $\left(25000 \mathrm{~g}, 30 \mathrm{~min}, 4^{\circ} \mathrm{C}\right)$. This crude material was sterilised through a $0.22 \mu \mathrm{m}$ pore size membrane filter (Millipore) and stored at $4^{\circ} \mathrm{C}$. Toxin A was purified from this crude material as previously described ${ }^{11}$ using ammonium sulphate precipitation, preparative flat bed electrophoresis, and ion exchange chromatography. Toxin A was pure serologically and immunologically as judged by two dimensional immunoelectrophoresis using (a) pure toxin against antisera raised to crude toxins and (b) crude toxin against hyperimmune rabbit antisera raised to purified toxin. Only one polypeptide was observed on SDS/polyacrylamide gels developed using silver stain. Toxin B fractions from the flat bed electrophoresis system were pooled. This material still contained residual amounts of toxin A. Contaminating toxin A was removed from toxin B preparations by ion exchange on DEAE-cellulose as previously described. ${ }^{13}$ Toxin $\mathrm{B}$ preparations after this procedure were free of detectable toxin $\mathrm{A}$ by ELISA (limit of detection $5 \mathrm{ng} / \mathrm{ml})^{14}$ and were assayed for toxin B in the conventional cytotoxin/ tissue culture assay ${ }^{15}$ (we used mouse L-929 cells). Toxin B preparations were found to contain at least four polypeptides on silver stained polyacrylamide gels and are therefore referred to as partially purified' toxin B.

\section{CHOLERA TOXIN}

This was obtained from Sigma Fine Chemicals.

\section{RABBIT ILEAL AND COLONIC LOOPS}

Ileal loop $(6 \mathrm{~cm})$ tests were done as previously described. ${ }^{16} \mathrm{~A}$ method was developed for constructing closed loops in rabbit colon. The luminal contents of the upper colon were washed into the lower colon by cannulating the gut at the caecal/ colonic junction and slowly pumping $100 \mathrm{ml}$ isotonic saline into the lumen with a peristaltic pump. From the point of ligation three $6 \mathrm{~cm}$ ligated loops with 2 $\mathrm{cm}$ interloop spaces were constructed. The first loop received toxin $\mathrm{A}$, the second phosphate buffered saline (PBS: $4.25 \mathrm{~g} / 1 \mathrm{NaCl}, 2.44 \mathrm{~g} / 1 \mathrm{KH}_{2} \mathrm{PO}_{4}, 8.09 \mathrm{~g} / \mathrm{l}$ $\left.\mathrm{Na}_{2} \mathrm{PO}_{4}, \mathrm{pH} 7\right)$ and the third received cholera toxin $(2.5 \mu \mathrm{g})$. Sample volumes of $0.5 \mathrm{ml}$ were used in all loops which were examined at 12 hours unless otherwise stated. Results were recorded as volume of fluid taken from loop/length of loop (V/L; $\mathrm{ml} / \mathrm{cm})$.

\section{TOTAL PROTEIN DETERMINATION}

Protein concentrations of loop contents were made by an automated biuret method (A-Gent total protein test, Abbott Laboratories).

DETERMINATION OF PLASMA PROTEIN LEAKAGE To determine whether luminal protein was vascular in origin, the method of Ohishi and Odagiri ${ }^{17}$ for measuring extravasation of plasma protein in mice was adapted for use in rabbits. Evans blue dye (Sigma) was given intravenously $(4 \%(\mathrm{w} / \mathrm{v})$ in saline; $1 \mathrm{ml} / \mathrm{kg}$ body weight) immediatley after inoculation of toxin into the loop. Animals were killed at various time points and the $\mathrm{V} / \mathrm{L}$ ratios calculated. Collected fluid was diluted 1 in 4 in $10 \%(w / v)$ sodium dodecyl sulphate to dissolve mucus and centrifuged $\left(2000 \mathrm{~g}, 20 \mathrm{~min}, 4^{\circ} \mathrm{C}\right)$ to remove particulate matter. The extravasated Evans blue dye was determined (after further dilution in water if necessary) spectrophotometrically at $620 \mathrm{~nm}$. One extravasation unit was defined arbitarily as one absorbance unit of undiluted loop material; total extravasation units/cm length of loop $(\mathrm{EU} / \mathrm{cm})$ were calculated from $\mathrm{V} / \mathrm{L}$ ratios $\times$ total dilution of sample $\times$ Absorbance at $620 \mathrm{~nm}$ (1 cm light path).

\section{TIME COURSE EXPERIMENTS}

The time course of fluid accumulation, protein accumulation, plasma protein leakage, and tissue damage were monitored in the rabbit ileal and colonic loop models. Twenty four rabbits were used in each time course experiment. Logistical considerations limited the handling of rabbits to six in any one day. Each of six rabbits received a range of four concentrations of toxin A in separate ileal loops, and, in one loop $2 \cdot 5 \mu \mathrm{g}$ cholera toxin; PBS was used as a negative control. A total of six loops were constructed in any one rabbit. At two hour intervals rabbits were killed and fluid accumulation ratios and total protein values measured. This was repeated in another six rabbits. A third group of six rabbits was treated in a similar manner to the first except that Evans blue dye was injected as described above; this was necessary because the Evans blue dye interfered with total protein assays. From these animals, V/L ratios and Evans blue dye contents of luminal fluids were measured. This was repeated in another six rabbits.

Time course studies were also made using the colonic loop model. The methods used for colonic time course studies were the same as for those described for the ileal study except that only three loops were constructed in each rabbit. One loop served as a negative control (PBS), one for cholera toxin $(2 \cdot 5 \mu \mathrm{g})$ and one for $C$ difficile toxin $(10 \mu \mathrm{g}$ toxin A or $10^{5}$ cytotoxic units of toxin B). These values for $C$ difficile toxins were based on the ileal loop results. For each of the time points in Figures 1 , 2 , and $3 \mathrm{~V} / \mathrm{L}$ ratios were plotted as the mean of 


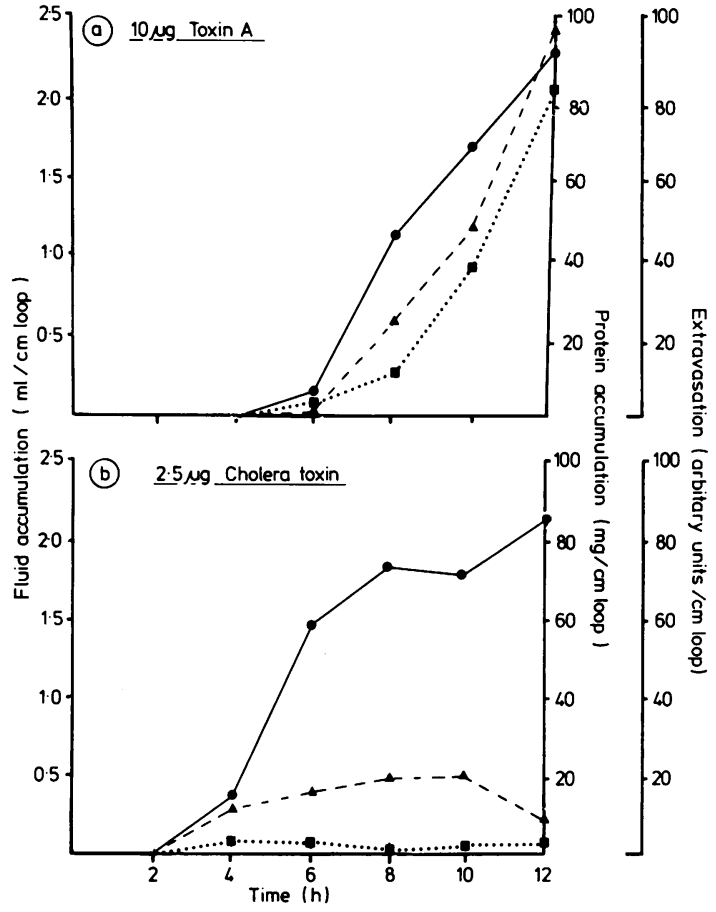

Fig. 1 Time course of response of rabbit ileum to (a) $10 \mu \mathrm{g}$ of purified toxin $A$; (b) $2.5 \mu \mathrm{g}$ cholera toxin.

: Fluid accumulation $(\mathrm{ml} / \mathrm{cm})$; each time point represents the mean of data from four animals.

$\Delta----\Delta$ : Protein accumulation $(\mathrm{mg} / \mathrm{cm})$; each time point represents the mean of data from two animals.

口.......... Extravasation of plasma protein (arbitary

units $(\mathrm{cm}$ ); each time point represents the mean of data from two animals.

values from four animals; total protein and extravasation unit data were the means of values from two animals.

\section{HISTOLOGICAL STUDIES}

Segments of ligated loops were taken at each time point and fixed in $10 \%$ formal saline. The tissues were embedded in paraffin wax, sectioned and stained with haematoxylin and eosin for examination by light microscopy.

\section{Results}

\section{ILEAL LOOPS}

Time course studies

Secretion of viscous, bloody fluid started in ileal loops inoculated with toxin $A$ at approximately six hours (Fig. 1a). Cholera toxin induced secretion of watery fluid beginning at approximately two hours (Fig. 1b). Negative control loops remained undis-

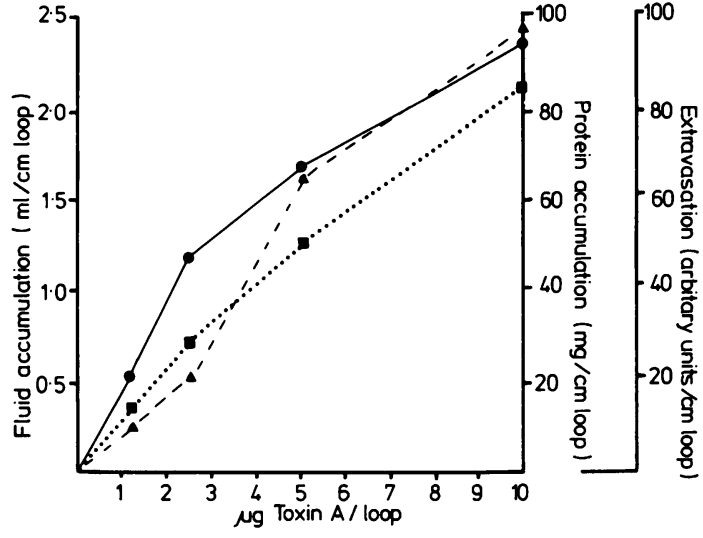

Fig. 2 Response of rabbit ileum to varying doses of purified toxin A. Results were read at 12 hours.

: Fluid accumulation $(\mathrm{ml} / \mathrm{cm})$; each time point represents the mean of data from four animals.

$\Delta----\mathbf{\Delta}$ : Protein accumulation $(\mathrm{mg} / \mathrm{cm}) ;$ each time point represents the mean of data from two animals. -......... Extravasation of plasma protein (Arbitary units $/ \mathrm{cm})$; each time point represents the mean of data from two animals.

tended at all time points. Accumulation of fluid in the loops coincided with accumulation of increasing amounts of protein (Fig. 1a). On the basis of the appearance of Evans blue dye in the luminal contents it would appear that the protein was derived from the plasma. In contrast, cholera toxin caused an influx of clear watery fluid with very little

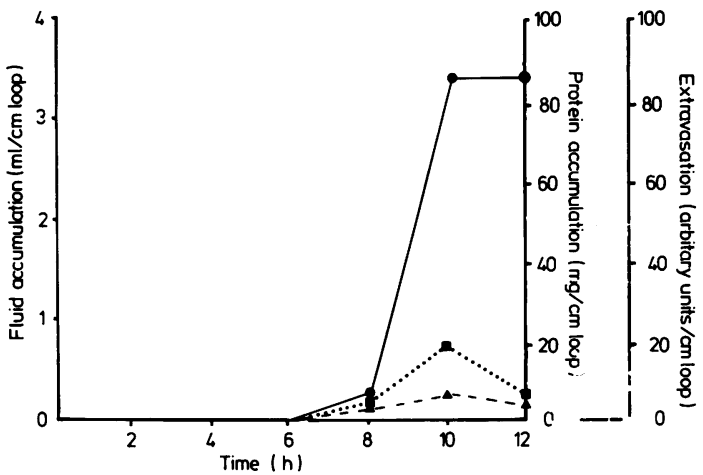

Fig. 3 Time course of response of rabbit colon to $10 \mu \mathrm{g}$ of purified toxin $A$.

: Fluid accumulation $(\mathrm{ml} / \mathrm{cm})$; each time point represents the mean of data from four animals.

$\Delta----\Delta$ : Protein accumulation $(\mathrm{mg} / \mathrm{cm}) ;$ each time point represents the mean of data from two animals. -........... Extravasation of plasma protein (Arbitary units $(\mathrm{cm})$; each time point represents the mean of data from two animals. 
leakage of Evans blue dye. Histological examination of tissue taken at two hour intervals showed that both negative control and cholera toxin loops were morphologically normal up to 12 hours of incubation (Fig. 5a). Toxin A treated loops showed damage to the intestinal epithelium by two hour post inoculation although fluid accumulation had not begun by this time. Histological changes became more severe with time, ranging from slight damage to the villus tips to extensive destruction of villus architecture; by six hours secretion became overtly manifest. By 12 hours there was a severe inflammatory response and haemorrhagic necrosis of the mucosa (Fig. $5 b-e)$.

\section{Dose response studies}

The response of ileum to toxin $\mathrm{A}$ was dose dependent (Fig. 2): a secretory response was achieved with $2 \mu \mathrm{g}$ of toxin A, but as little as $500 \mathrm{ng}$ elicited histological damage (Fig. 4). Responses similar to those shown in Figures 1a, 2, and 5 for purified toxin A were observed in ileum when equivalent amounts (as determined by ELISA) of crude concentrated culture filtrate were used. Amounts of toxin A greater than $100 \mu \mathrm{g}$ loop were found to be lethal to rabbits after 12 hours.
Inoculation of ileal loops with equivalent amounts that is, $10^{5}$ cytotoxic units - of crude concentrated culture filtrate and partially purified toxin B showed toxin B failed to cause fluid accumulation (Table) or tissue damage in the ileum (histology not shown Fig. 5a) as not distinguishable from control.

\section{COLONIC LOOPS}

\section{Time course studies}

Toxin A caused fluid accumulation in colonic loops. Onset of fluid accumulation occurred post eight hours (Fig. 3). Final loop ratios were higher than ileal equivalents but this reflects the greater diameter of colon compared with that of ileum. Neither cholera toxin $(2.5 \mu \mathrm{g})$ nor partially purified toxin B $\left(10^{5}\right.$ cytotoxic units) had any effect when injected into colonic loops; the latter remained flat and are histologically similar to control (Fig. 6a).

The time course of histological changes in colon treated with toxin A was similar to that seen in the ileum, with tissue damage being apparent at two hours and progressing to extensive damage by 12 hours (Fig. 6b). Colon treated with toxin A, however, showed substantially less haemorrhage and the degree of cellular infiltration was also less than in ileum. The fluid from colonic loops was

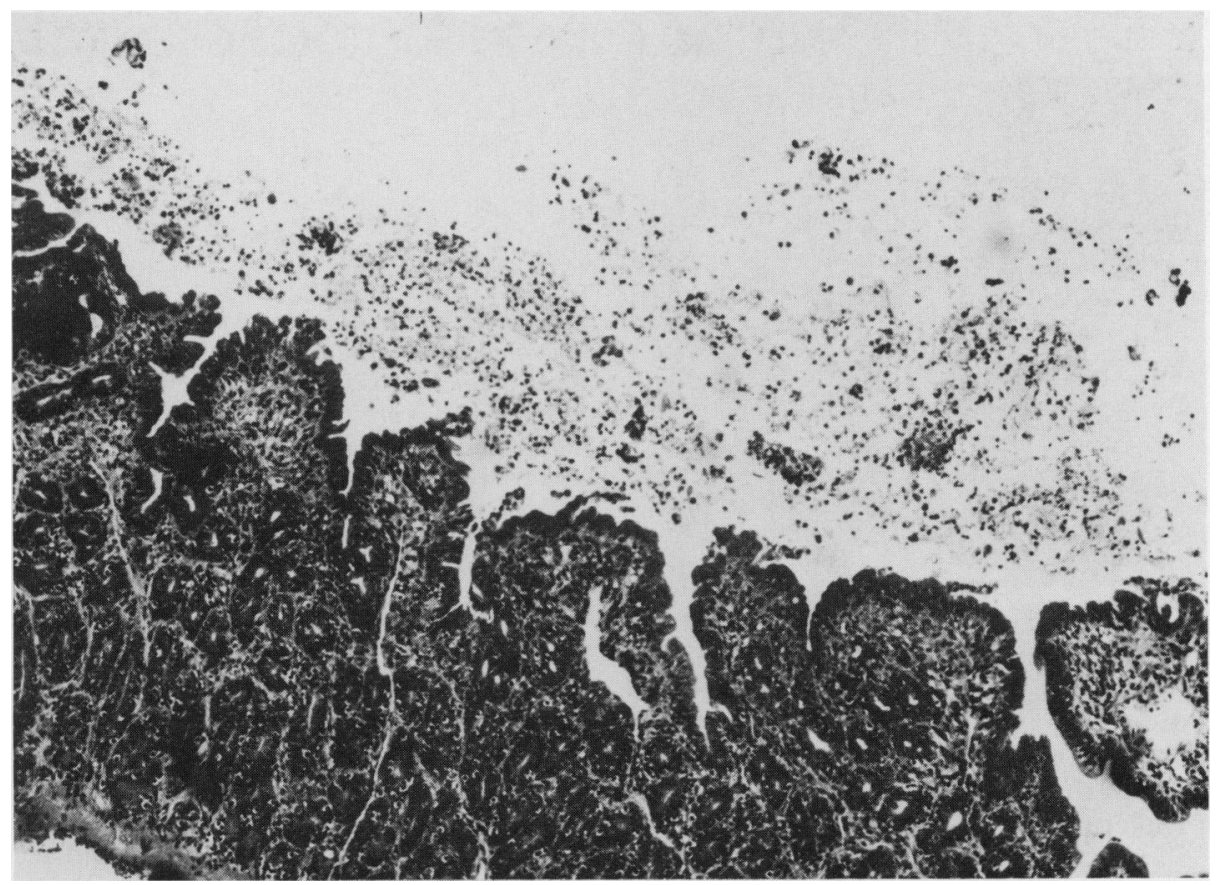

Fig. 4 Histological response of rabbit ileum to $500 \mathrm{ng}$ purified toxin $A$ after 12 hours incubation $(H$ and $E ; \times 150$ original magnification). 


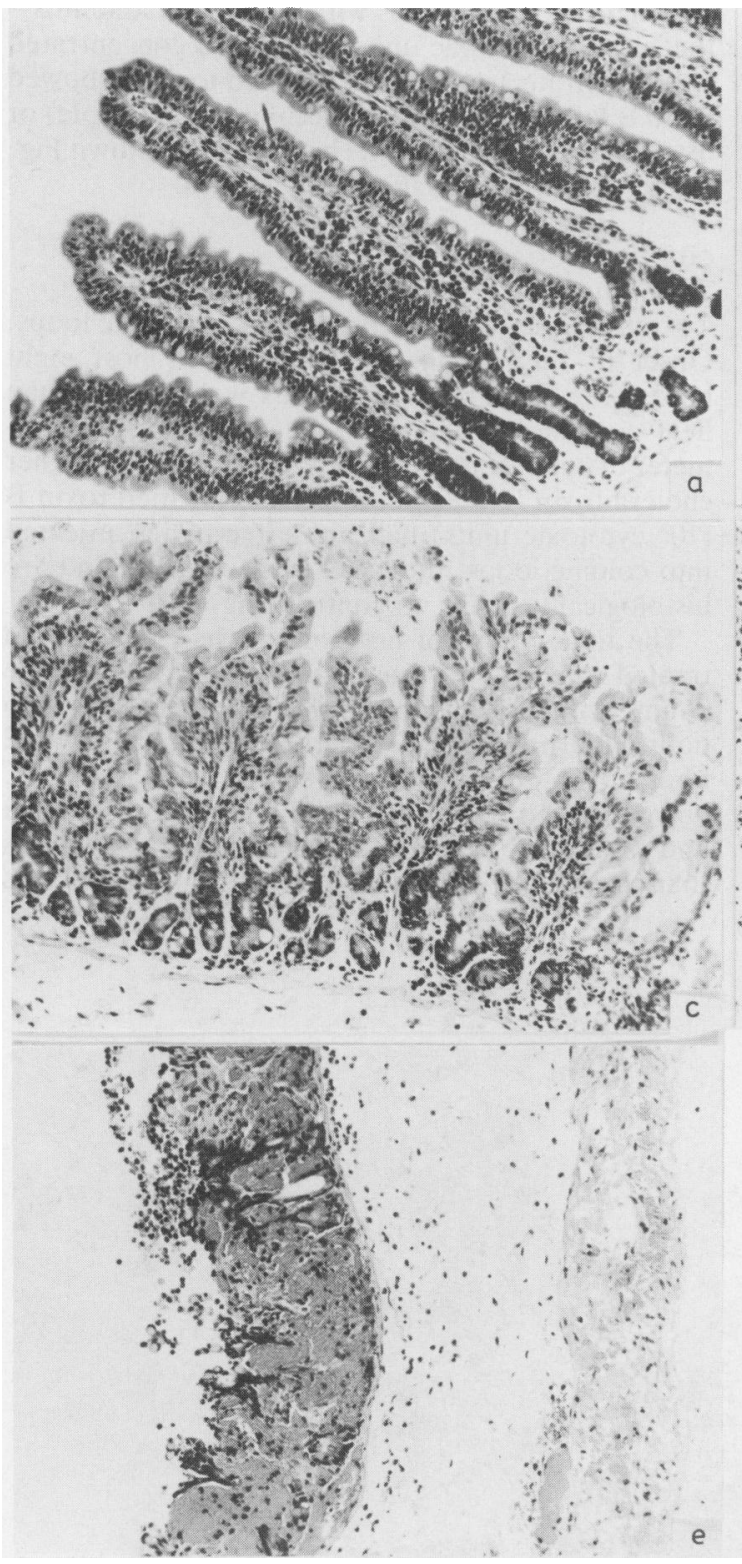

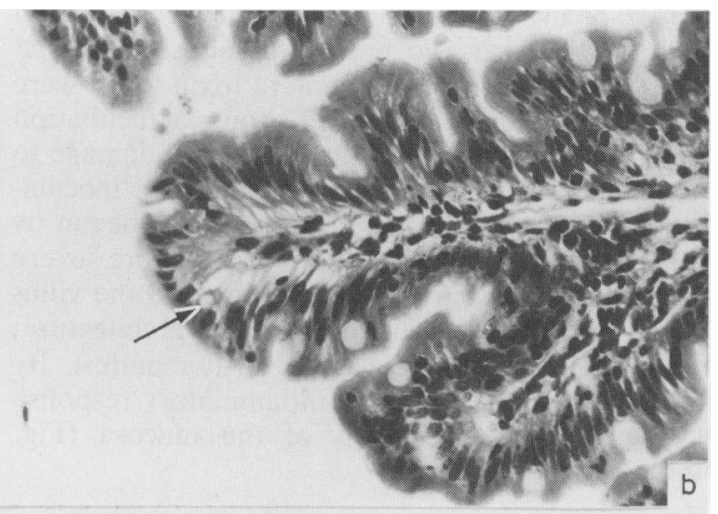

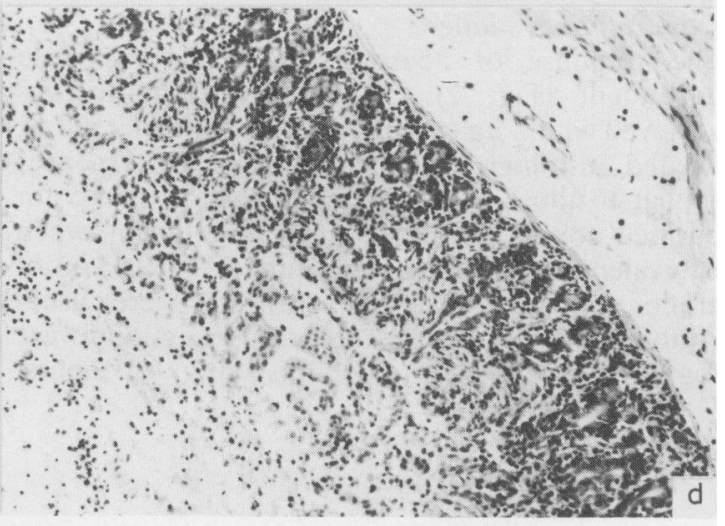

Fig. 5 Histology of toxin treated ileum. Ileal tissue incubated with (a) saline and (b), (c), (d), (e) with $10 \mu \mathrm{g}$ toxin $A$ for 2, 4, 6, 12 hours respectively. ( $H \&$ E; all magnifications are $\times 150$ original except $(b) \times 675)$. Shortening of the villi and some cellular damage (arrow) can be seen at 2 hours. This progresses to damage to villus tips by $4 \mathrm{~h}$ and extensive destruction of the villi at $6 \mathrm{~h} .8 \mathrm{~h}$, and $10 \mathrm{~h}$ time points showed extensive damage and haemorrhage similar to that seen at $12 \mathrm{~h}$. visibly less bloody than that from ileal loops. Amounts of protein and Evans blue dye accumulating in colonic loops (Fig. 3) were also lower than that observed in the ileal study and more resembled effects of cholera toxin in ileum (Fig. 1b).

\section{Discussion}

This study indicates that toxin A induces morpholo- gical changes in rabbit ileum before the onset of fluid accumulation. Damage increases progressively from localised damage to the villus tips to eventual destruction of villi and gross haemorrhage. The histological effects of toxin A are in marked contrast with cholera toxin which induces fluid accumulation but does not cause any apparent damage to the intestine. These data suggest that the secretory response in rabbit ileum induced by $C$ difficile toxin 
Table Comparison of the effects of equivalent amounts of crude concentrated culture filtrate, purified toxin $A$ and partially purified toxin $B$ on the rabbit ileum after 12 hours incubation. Purified toxin $A$ has a similar effect to an equivalent amount of crude concentrated culture filtrate. Toxin B had no effect on the ileum. V/L data are the mean of data from four animals and protein and $E U$ data are the mean of data from two animals (for explanation see text). Errors are expressed as standard deviation from the mean and are representative of the whole data

\begin{tabular}{|c|c|c|c|}
\hline & $V / L(\mathrm{ml} / \mathrm{cm})$ & Protein $(\mathrm{mg} / \mathrm{cm})$ & $E U($ units $/ \mathrm{cm})$ \\
\hline \multicolumn{4}{|c|}{ Crude concentrated culture filtrate } \\
\hline $\begin{array}{l}10 \mu \mathrm{g} \text { toxin } \mathrm{A} \\
10^{5} \text { units toxin } \mathrm{B}\end{array}$ & $1 \cdot 95 \pm 0 \cdot 1$ & $66 \cdot 5 \pm 1 \cdot 65$ & $80 \pm 10$ \\
\hline $\begin{array}{l}10 \mu g \text { purified } \\
\text { toxin } A\end{array}$ & $2 \cdot 30 \pm 0 \cdot 2$ & $98 \cdot 4 \pm 5 \cdot 40$ & $83 \pm 13$ \\
\hline $\begin{array}{l}10^{5} \text { units partially } \\
\text { purified toxin } B\end{array}$ & $0 \cdot 20 \pm 0 \cdot 1$ & $-(a)$ & - (a) \\
\hline
\end{tabular}

(a) Volumes taken from these loops were too small to allow determination of protein and extravasation data

A is due initially to a cytopathic effect of the toxin on the enterocytes, and later to effects on the blood vessels giving rise to the haemorrhage; the latter is a marked characteristic of toxin induced damage in rabbit ileum. Toxin $\mathrm{A}$ also induces extensive extravasation of Evans blue dye into the ileal lumen, whereas fluid secreted in cholera toxin treated loops contained only small amounts of the dye. The pattern of accumulation of extravasated dye coincided with that of luminal protein and increases in volume of fluid in the lumen, indicating that the source of protein in secreted fluid is plasma. This suggests that the secretory response to toxin $\mathrm{A}$ is because of an increase in permeability of the intestinal mucosa. The permeability change in the gut is preceded by tissue damage which in turn suggests that the permeability change in the gut is almos: certainly a direct result of tissue damage. Toxin A also causes increased vascular permeability in guinea pig skin, ${ }^{9}$ a finding which is consistent with the effects of the toxin on the permeability of the gut. The effect of toxin $\mathrm{A}$ on rabbit ileum thus appears to be similar to the effect of botulinum type $\mathrm{C}_{2}$ toxin on mouse intestine reported by Ohishi and Odagiri. ${ }^{17}$ Toxin $\mathrm{A}$ is also similar to $C$ perfringens enterotoxin which induces tissue damage at concentrations of toxin needed to induce fluid accumulation. ${ }^{18}$ (It should be pointed out that Ohishi and Odagiri $^{17}$ refer to McDonel and Duncan ${ }^{18}$ in claiming that $C$ perfringens enterotoxin induces fluid accumulation before the appearance of tissue damage. The data of McDonel and Duncan ${ }^{18}$, however, indicate that fluid secretion does not occur in the absence of tissue damage).

Data on the effect of enterotoxins on the colon are few and contradictory. For example, cholera toxin has been reported ${ }^{19}$ to cause net fluid secretion in colonic loops as judged by perfusion studies. In contrast, other perfusion studies show that cholera toxin does not affect movement of fluid in the colon..$^{2021}$ In our studies, however, on closed colonic loops cholera toxin did not cause fluid accumulation at concentrations which routinely caused full distention of ileal loops. Taylor and coworkers ${ }^{9}$ claim that toxin A causes tissue damage in hamster colon, ileum, and caecum. Fig. 2 in Taylor et al ${ }^{9}$ shows histological damage to hamster ileum whereas Bartlett and Taylor ${ }^{22}$ reproduce exactly the same figure (Fig. 4a) and describe it as damaged hamster colon. We report here for the first

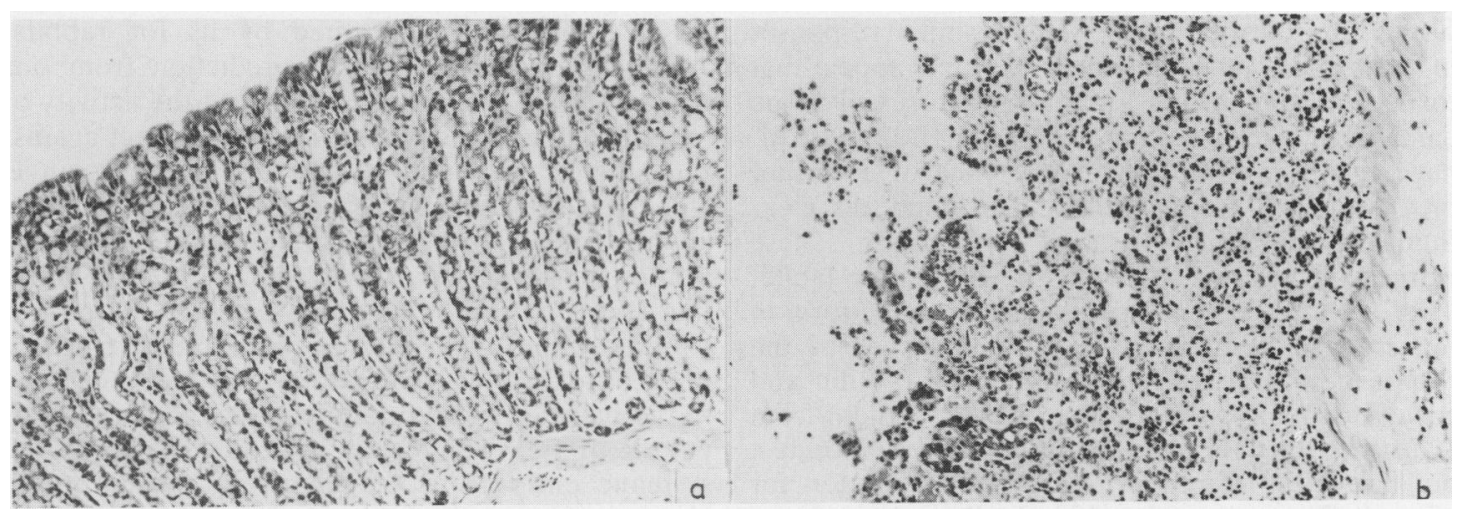

Fig. 6 Histology of toxin treated colon. Colonic tissue incubated for 12 hours with (a) saline and (b) $10 \mu \mathrm{g}$ toxin A. (H\& E; $\times 150$ original magnification). Shows extensive damage to colon, but with less haemorrhage than in similarly treated ileum. 
time the results of a controlled study on the effects of $C$ difficile toxins $\mathrm{A}$ and $\mathrm{B}$ on rabbit colon. Toxin A causes fluid accumulation in the rabbit colon to a similar extent as in the ileum whereas partially purified toxin $\mathrm{B}$ had no observable effects on the colon. There were, however, important differences found in the response of ileum and colon to toxin A, which may have significance in relation to clinical findings.

Fluid accumulated in colonic loops in response to toxin A had a different composition to that from ileal loops; it contained less protein and was also less bloody. Toxin A also caused less extravasation of Evans blue dye in the colon. Histological examination showed toxin A to cause extensive damage in the colon but the extent of cellular infiltration and haemorrhage was less than in the ileum. As there is no difference in fluid accumulation ratios between ileum and colon, it is concluded that toxin $A$ induces a more watery secretion in the colon. These findings may help to interpret the clinical picture seen in the majority of patients with $C$ difficile associated diarrhoea. For example, most patients excrete mainly watery stools, only a few are bloody. Our results predict that major colonic, as distinct from ileal, involvement would give rise to a predominantly watery diarrhoea. This would especially be the case in the unobstructed large bowel which, in an induced secretory state, would have diminished capacity to handle small bowel outflow. In other patients (with no immediate previous history of diarrhoea) examined at necropsy, evidence of damage to colonic mucosa can be found. From our results it is clear that a certain degree of tissue damage can occur without fluid secretion - that is, the latter happens only after a progression beyond a hitherto undefined degree of damage. Because equivalent amounts of crude concentrated culture filtrate and purified toxin $\mathrm{A}$ gave similar responses in ileum and colon respectively, it would appear that toxin $\mathrm{A}$ is responsible for the secretion and tissue damage induced by crude material. Banno et $a l^{6}$ have recently reported the existence of a further factor, distinct from toxin $\mathrm{A}$ which induces clear fluid accumulation in rabbit ileal loops. These workers report the factor to be extremely labile. This factor is either not present in an active form in our crude material or its activity is masked by the response of the tissue to toxin A. Also Rihn and coworkers $^{23}$ have reported isolating a protein from $C$ difficile which is active in the rabbit ileal loop test but has different properties to those reported for toxin $\mathrm{A}$. The toxin isolated by the Rihn group has a relatively low molecular weight $(52000)$, a low isoelectric point (3.5) and is composed of two subunits (molecular weights 41500 and 16000 ).
These characteristics are different from those reported for toxin A which has a molecular weight of 440000 to 500000 , an isoelectric point of 5.5 and cannot be resolved into subunits. ${ }^{13}$ Rihn et al ${ }^{23}$ state that the toxin is active in the rabbit ileal loop test but do not state whether the toxin causes tissue damage. The relationship between this toxin and toxin $\mathrm{A}$ is unclear.

Our findings question the role of toxin $\mathrm{B}$ in tissue damage and secretion; partially purified toxin $B$ had no effect on ileum or colon. Lonnroth and Lange, ${ }^{24}$ however, state that in mouse ileal loops toxin A alone causes clear fluid accumulation, toxin $\mathrm{B}$ alone has no effect, but a combination of purified toxins $A$ and $B$ causes a haemorrhagic hypersecretion. These workers propose that tissue necrosis is because of the combined action of toxin $\mathrm{A}$ and a heat labile factor which may be toxin B itself or may be an additional factor which copurifies with toxin B. These results are in contrast with our data and those of other workers ${ }^{910}$ who report homogenous preparations of toxin A to cause an haemorrhagic secretory response in rabbit ileum. These differences may be explained by the different animal species used.

The previous discussion excludes toxin $\mathrm{B}$ from having a role in the pathogenesis of $C$ difficileinduced diarrhoea. Our data may also provide some insight to the lethal effects of this organism in some patients and in experimental animals. ${ }^{12}$

At first sight, our results make it difficult to interpret the data of Libby and coworkers ${ }^{12}$ who showed that effective protection of hamsters against a lethal, clindamycin-induced caecitis - that is, a presumptive $C$ difficile infection - was only achieved when animals were immunised against both toxins $A$ and B. While there is no doubt that toxin B is lethal when given parenterally in several animal spe$\operatorname{cies}^{12} 25$ (and also confirmed by us for rabbits; unpublished data), a simple prediction from our data would be that protection against the activity of toxin A alone would be sufficient to protect against a combined challenge at least in rabbits; toxin B alone has no demonstrable enteric activity in our animal model. The need for immunity to both toxins in the hamster caecitis model may be explained by the fact that Libby and coworkers ${ }^{12}$ found, in contrast with Taylor and coworkers, ${ }^{9}$ that partially purified toxin B caused considerable tissue damage in the hamster caecum, and was also lethal via this enteric route. Thus toxin B could have gained systemic entry from the hamster caecum in the absence of active toxin $\mathrm{A}$. In the rabbit, however, and in any other species in which toxin $B$ has no enteric activity, toxin B could only express its lethal activity if absorbed systemically and this would only 
be possible as a sequel to the destructive activity of toxin $\mathrm{A}$.

JS, DWB, and DCAC wish to thank Pfizer Central Research and SERC for CASE studentship to TJM and the MRC for research fellowship to $\mathrm{SCH}$ and studentship to JMK.

\section{References}

1 Bartlett JG, Onderdonk AB, Cisneros RL, Kasper DL. Clindamycin associated colitis due to a toxin-producing species of Clostridium in hamsters. J Infect Dis 1977; 136: 701-5.

2 George RH, Symonds JM, Dimmock F et al. Identification of Clostridium difficile as a cause of pseudomembranous colitis. $\mathrm{Br}$ Med J 1978; 1: 695.

3 Bartlett JG, Taylor NS, Chang TW, Dzink JA. Clinical and laboratory observations in Clostridium difficile colitis. Am J Clin Nutr 1980; 33: 2521-6.

4 Taylor NS, Thorne GM, Bartlett JG. Separation of an enterotoxin from the cytoxin of Clostridium difficile. [Abstract] Clin Res 1980; 28: 285A.

5 Justus PG, Martin JL, Goldberg DA et al. Myoelectric effects of Clostridium difficile: motility altering factors distinct from its cytotoxin and enterotoxin in rabbits. Gastroenterology 1982; 83: 836-43.

6 Banno Y, Kobyashi T, Kono H, Watanabe K, Uena K, Nozawa Y. Biochemical characterization and biologic actions of two toxins (D-1 and D-2) from Clostridium difficile. Rev Infect Dis 1984; 6: S11-S20.

7 Elliot HL, Carpenter CCJ, Sack RB, Yardley JH. Small bowel morphology in experimental cholera. Lab Invest 1970; 22: 112-20.

8 Moon HW, Whipp SC, Baetz AL. Comparative effects of enterotoxins from Escherichia coli and Vibrio cholerae on rabbit and swine intestine. Lab Invest 1971; 25: $133-40$.

9 Taylor NS, Thorne GM, Bartlett JG. Comparison of two toxins produced by Clostridium difficile. Infect Immun 1981; 34: 1036-43.

10 Lyerly DM, Lockwood DE, Richardson SH, Wilkins TD. Biological activities of toxins A and B of Clostridium difficile. Infect Immun 1982; 35: 1147-50.

11 Stephen J, Redmond SC, Mitchell TJ et al. Clostridium difficile enterotoxin (toxin A): new results. Biochem Soc Trans 1984; 12: 194-5.

12 Libby JM, Jortner BS, Wilkins TD. Effects of the two toxins of Clostridium difficile in antibiotic-associated cecitis in hamsters. Infect Immun 1982; 36: 822-9.

13 Sullivan NM, Pellett S, Wilkins TD. Purification and characterization of toxins A and B of Clostridium difficile. Infect Immun 1982; 35: 1032-40.

14 Redmond SC, Ketley JM, Mitchell TJ, Stephen J, Burdon DW, Candy DCA. Detection of Clostridium difficile enterotoxin (toxin A) by ELISA and other techniques. Technical Series Number 21. Isolation and identification of organisms of medical and veterinary importance. Collins $\mathrm{CH}$, Grange JM, eds. Society of Applied Bacteriology. London: Academic Press, 1985: 237-50.

15 Chang TW, Lauermann M, Bartlett JG. Cytotoxicity assay in antibiotic associated colitis. $J$ Infect Dis 1979; 140: $765-770$.

16 Evans DG, Evans DJ, Pierce NF. Differences in the response of rabbit small intestine to heat-labile and heat stable enterotoxins of Escherichia coli. Infect Immun 1973; 7: 873-80.

17 Ohishi I, Odagiri Y. Histopathological effect of botulinum $\mathrm{C}_{2}$ toxin on mouse intestines. Infect Immun 1984; 43: 54-8.

18 McDonel JL, Duncan CL. Histopathological effects of Clostridium perfringens enterotoxin in the rabbit ileum. Infect Immun 1975; 12: 1214-8.

19 Donowitz M, Binder HJ. Effect of enterotoxins of Vibria cholerae, Escherichia coli and Shigella dysenteriae Type 1 on fluid and electrolyte transport in the colon. J Infect Dis 1978; 134: 135-43.

20 Swallow JH, Code CF, Freter R. Effect of cholera toxin on water and ion fluxes in the canine bowel. Gastroenterology 1968; 54: 35-40.

21 Sack RB, Carpenter CCJ, Steenbers RW, Pierce NF. Experimental cholera; a canine model. Lancet 1966; 2: 206-7.

22 Bartlett JG, Taylor NS. Antibiotic-associated colitis. In: Easmon CSF, Jeljaszewicz J, eds. Medical Microbiology. Vol 1. London: Academic Press, 1982: 1-48.

23 Rihn B, Scheftel JM, Girardot R, Monteil H. A new purification procedure for Clostridium difficile enterotoxin. Biochem Biophys Res Commun 1984; 124: 690-5.

24 Lonnroth I, Lange S. Toxin A of Clostridium difficile: production, purification and effect in mouse intestine. Acta Pathol Microbiol Scand [B] 1983; 91: 395-400.

25 Arnon SS, Mills DC, Day PA, Henrickson RV, Sullivan NM, Wilkins TD. Rapid death of infant rhesus monkeys injected with Clostridium difficile toxins $\mathbf{A}$ and B: Physiologic and pathologic basis. J Pediatr 1984; 104: 34-40. 